\title{
Barriers in Implementation of Wastewater Reuse: Identifying the Way Forward in Closing the Loop
}

\author{
J. C. Morris ${ }^{1}$ (D) I. Georgiou ${ }^{1,2} \cdot$ E. Guenther ${ }^{1,2} \cdot$ S. Caucci ${ }^{2}$
}

Received: 11 February 2021 / Accepted: 23 February 2021 / Published online: 19 March 2021

(C) The Author(s) 2021

\begin{abstract}
The business case for circular economy in water management perspective has gain relevance in the recent times. By 2030, it is estimated that $160 \%$ of global total available water will be required to satisfy demand of anthropogenic-related activities and increasing waste-related water will be produced. Gaps on the conceptual framing of water reuse within supply chain management are clearly emerging and the demand for decision support systems helping at assessing effective water consumption in industrial setting is pressing. Despite the numerous local initiatives towards wastewater resource usage, barriers remain for its implementation in practice. Through a systematic review of previous studies in this field, the barriers towards the uptake of wastewater use in agriculture were classified according to the PESTEL (political, economic, social, technological, environmental and legal) framework. Alongside political and legal support, it is identified that for an economically and environmentally sustainable scheme for incentivising the deployment of feasible technologies, there is also a need to gain acceptance for wastewater usage in society in order to enhance the deployment of existing technological solutions. Addressing these factors in tandem can aid the development towards a circular economy for wastewater.
\end{abstract}

Keywords Wastewater · Barriers · Water management · Agriculture · Closing the loop

\section{Introduction}

Circular economy is one of the most important paradigms emerging in the research of industrial activity, focusing on a system for industrial and commercial activity which is

\section{J. C. Morris}

jonathan_clive.morris@tu-dresden.de

1 Chair of Sustainability Management and Environmental Accounting, Faculty of Business Management and Economics, Technische Universitaet Dresden, 01069 Dresden, Germany

2 United Nations University-Institute for Integrated Management of Material Fluxes and of Resources (UNU-FLORES), 01067 Dresden, Germany 
regenerative and restorative at the same time [1]. The circular approach is a challenge to the linear economy based on the principles of take-make-use-destroy [2] and is supported by various political aims, such as the European Union's Action Plan for a Circular Economy [3, 4].

From an operations management perspective, the business case for circular economy has grown in response to the rising costs of raw materials and the associated environmental impacts of by-products and non-sustainable waste management [5]. The finite nature of natural resources leads to the conceptualisations of resource efficiency and resource management, where the circular economy becomes a logical conclusion of the reduce, reuse and recycle perspective of sustainability [6]. The idea of circularity therefore can serve as a solution to the need for long-term sustainability management of natural resources.

Sustainable water management is a key for the World development. Subsequently, policymakers and the scientific community [7, 8] have been increasingly engaging with the topic. Recently, the European Commission drafted the 'A Resource Efficient Europe' action plan referred towards the integration of water resources to be included into measurements of resource efficiency and called for a step towards the collection of statistics that record the efficient use of abstracted water $[4,8,9]$. This is in response to projections of increased water stress and shortage, and it is estimated that by the year 2030, more than $160 \%$ of the total available water volume in the world will be required to satisfy global water requirements [10]. Globally, this would lead to $47 \%$ of the world's population living in high areas of water stress [7]. This calls for more inventive and currently unconventional methods for utilising water more effectively.

Under climate change perspectives, businesses are expected to use and manage water more efficiently, especially after water stress being identified as a 'supply chain risk' to national economies [11]. The increasing number and severity of droughts at the global level will present threats for businesses encompassing not only the water provisioning but also the reputational and regulatory pressures for industries with consequential increased stakeholders conflict. The extent of the risks arising from these pressures proportionally increases with the degree of reliability on water by companies. It clearly appears therefore that companies with high water use like food and beverage producers, textiles and mining companies [8] will be the first sectors hit by this problem. Water reuse examples in industrial processes have been demonstrated for agricultural and agro-industries [12], for the brewing industry [13] and textile industry [14]. However, a widespread adoption of such practices is not yet there as it requires collaboration and consent from policymakers and regulators, consumers, business leaders as well as technological capacity to roll-out these solutions on a wider scale [8].

Water sustainability approaches attempt to reconcile the consumption of freshwater with economic growth and societal development $[15,16]$ but do not account for a proper closing of the loop in the operational water cycle which is required for identifying pathways to circularity. Taking a sectoral specific perspective, agriculture is currently the largest user of water at the global level, accounting for more than $70 \%$ of total withdrawal [7]. Agriculture is also the largest consumer of wastewater or treated wastewater worldwide [17, 18] and offers an important case study to investigate the opportunity of a water-intensive industry. Specifically, use and provision of wastewater for irrigation purposes can alleviate the on-site demand pressure on agro-industrial activities and ensure the continuity of the supply chain thus maintaining food security. A circular economy approach within the consumption of wastewater for agriculture presents another opportunity to increase water sustainability in economic 
systems by identifying the transferrable lessons which can be applied in a wider business perspective.

Nevertheless, a successful implementation of wastewater treatment in agriculture depends on several factors drawing upon technological capabilities, modifying existing systems to accommodate wastewater systems and gaining acceptance from political leaders and wider society. In this study, we aim at synthesising and analysing the existent knowledge driving the understandings and conceptions of water reuse in agricultural processes, with the intent of developing a framework that could aid the upscaling of such practices for industrial contexts for an improved short-term system resilience in time of Global Change. This requires addressing not only societal and political barriers to change but to also identify feasibility barriers relating to the environment, the economy and the financial viability of existing and available technologies.

Focus of the study will be oriented to barriers and opportunities of water reuse and strategic water management for the implementation of sustainable options of water reuse in agriculture/ agro-industrial sectors. Impacts and relationships among factors influencing water reuse will be highlighted and divided according to the economic, environmental and social pillars of sustainability, and taking a resource efficiency lenses and circular economy transitioning processes. Despite there being no doubt on the essential role of water in sustaining life and valuing economic activities, water management remains one of the biggest challenges for a shift towards circularity. The water reuse concept would help to alleviate water stresses and scarcities as water demands continue to outstrip traditional sources of freshwater supply. To shed light on the potential path for water reuse implementation under circular economy understandings, the analysis presented in this paper addresses the research questions:

- What are the challenges related to the implementation of water reuse in agriculture?

- Is there any difference in the conceptual understanding of water reuse (implementation) between stakeholders?

- Can the identified opportunities and barriers be 'scaled-up' to various industrial sectors?

The study makes use of the systematic review methodology on peer-reviewed research on Scopus and Web of Science using keywords related to water reuse, wastewater and agriculture. The paper is structured with an initial discussion of the theoretical underpinnings of wastewater as part of a water circular economy framework and on up-to-date wastewater uses in agricultural processes. The comprehensive overview on the outcomes shows how wastewater is an integral part of a water circular economy framework and will highlight avenues for future research on the definition of newer business models for in water management.

\section{Research Design and Theoretical Framework}

A circular economy approach within the use of wastewater presents the opportunity to increase water sustainability in economic systems. The perspective of ecological modernisation suggests that institutional, market and social reform can act as a catalyst towards a more harmonious and mutually reinforcing relationship between economic development, environmental protection and social development. Under this perspective, environmental efficiency of the economy can be achieved by reducing the rate of environmental stress caused per unit of output. Measuring progress under the ecological modernisation process is also associated with 
measures of resource productivity and eco-efficiency. These measures are not necessarily concerned with consuming less, but with consuming resources in a more efficient way, minimising waste and satisfying consumer demand. The limitation of this perspective is that processes complexity can increase and not always such complexity is taken into account by the stakeholders involved in the transitioning phase [19] towards a more sustainable system. Korhonen [20] highlights how: 'actors may need to learn how to appreciate that, at times, suboptimal outcomes at the level of an individual system component can be important for optimal long-term outcomes at the level of the larger system'. Spatial, temporal, cultural and social issues are embedded in how resource efficiency and sustainability concepts are developed at a national level, and how these developments affect social and environmental effects on the economy.

\section{Wastewater in the Context of Circularity}

Hobson and Lynch [21] compare circular economy to ecological modernisation describing how circular economy is an attempt to reconcile economy and environment to produce sustainable outcomes. Wastewater provides a steady, reliable and drought resistant source of water and can therefore contribute towards increased resilience and stability of water supplies. The importance of wastewater as a valuable resource rather than as a waste product required to be disposed of will only increase in the future [22]. In promoting further, the insights of wastewater as a resource, Hanjra et al. [23] highlight that not only will the demand for water increase in the future but correspondingly so will the amount of wastewater generated. The view of ecological modernisation is that the unlimited economic growth is possible and ecological crises can be averted through incorporating nature into economic processes through the use of technological changes and developing markets for practices which are less wasteful [24]. Under this framework, the availability of water or the volumes of waste emitted would no longer be a constrain on economic activity, and industry can continue to focus as before. Viewing wastewater use as a concept of ecological modernity therefore is dependent on processes that rely on innovative technologies and policies that enable the successful implementation of circular practices without radically altering the path of economic activity and growth [25].

In terms of water, the theory of ecological modernisation highlights how circular economy for water via an increased uptake of wastewater could help to achieve eco-efficiency goals (as a greater number of inputs can be generated by the same or lower amounts of freshwater inputs) and sustainability objectives. The production processes in many industries can be transformed to reduce the impact on the natural environment and available water resources. Promoting circular economy of water resources through the lens of an ecological modernisation framework should extend the productive lifespan of water resources whilst maintaining or enhancing the productivity of resource use. At the same time, building future utilities by shifting away from wastewater treatment plants to resource recovery facilities would help at realising the untapped value of waste into source for nutrient recovery and fertilising supplement for agriculture [26].

However, implementing ecological modernisation in practice through water reuse is not a risk-free process.

Whilst technical solutions may be available for providing the types of filtration, treatment and connectivity for wastewater use, barriers may arise in terms of cost, social acceptance, 
political will, environmental damage (for example, if the treatment process requires the use of harmful chemicals) and a lack of a legal framework.

Therefore, proposing circular usage of water requires a framework that goes beyond a reliance on technological solutions and instead considers a holistic perspective that encompasses politics and socio-environmental factors that are critical for successful implementation and deployment of such technologies and address the economic viability of such interventions $[24,27]$.

\section{Economic, Financial, Political and Legal Feasibility}

The study on the circular economy transitioning by Kirchherr et al. [28] highlights how technological feasibility is pre-requisite. Nevertheless, existing cases and consultation with business representatives highlighted how the economic and regulatory barriers to hamper circular economy transitioning. Economic barriers can be distinguished between long-term economic viability and short-term financial barriers. Access to finance is critical for the upfront investment costs but is often unfeasible for many companies [29, 30]. Up-front investment costs can deter potential first-movers in circular economy transitions, especially when continuing with existing practices utilising freshwater sources is significantly cheaper than reusing wastewater $[28,31]$. Beyond the financial viability of investing in wastewater use, a successful transition towards circular use of water needs to consider the long-term economic feasibility of deploying circular economy practices.

Political and regulatory feasibility is also related to the wider barriers and opportunities for the uptake of circularity in wastewater use and should be based on addressing the barriers which exist. For example, many firms, particularly smaller ones, are often incentivised to enact sustainable and circular activities in response to legal requirements [29], whilst the lack of supportive policy frameworks and legal mechanisms can impede on the widespread uptake of wastewater use [30]. However, overregulation and poorly developed legal frameworks which lack political support can hinder the uptake of wastewater use. Experiences in countries such as Colombia have shown how the lack of formal frameworks and descriptions reduces the ability to reach critical stakeholders if the bureaucratic requirements are too high [32]. However, welldesigned regulations can also be utilised to address environmental and social challenges which may arise from promoting the increase in wastewater reuse.

\section{Opportunities, Barriers and the PESTEL Framework}

To develop a circular framework involving wastewater use in practice, a full range of barriers and opportunities can be identified to maximise the opportunities for wastewater use. Here, we draw on the transition towards wastewater reuse and a water circular economy as a process innovation. In their review of innovation barriers, Hueske and Guenther [33] discuss classification of barriers which relate to technology, environment, organisational issues and individual preferences which cut across a number of stakeholder grouping. Barrier analysis has been applied successfully to the German biotechnology industry to identify internal organisational barriers towards developing process innovations and the key stakeholders that should be engaged with to overcome social and political barriers which may exist [34]. These barriers can be organisation-specific or exist at a wider scale [35], such as at societal level. Engaging in the process of discovering barriers and formulating strategies to overcome them 
can aid organisations in discovering new forms of best practices to overcome critical challenges and diffuse these practices into the operations of their supply chains and customers [36].

The study of Hueske and Guenther [34] highlights the importance of reducing complex barriers into barrier groups against which practical solutions can be applied. This process of grouping barriers according to interrelated and underlying factors can aid in the development of practical configurations which can be utilised to determine strategies for increasing the uptake of new technologies, such as those for increased wastewater reuse. One tool that can be used to identify the main factors which can impact on the successful implementation of a circular-oriented water strategy is a PESTEL analysis. A PESTEL analysis is an analytical tool for strategic business planning that aids in understanding the external influences on a business (or other organisational form). External impacts are classified into factors under broad headings of Political, Economic, Social, Technological, Environmental and Legal considerations and are applied to business strategic planning as well as policy planning settings.

PESTEL analyses can be applied to situations where new processes or strategies are to be applied and require identifying and classifying the potential impacts and barriers on such shifts and identify influential stakeholders that need to be engaged with to encourage shifts towards a circular wastewater system. In exploring research identifying potential barriers towards dealing with wastewater that links to socio-political and legal barriers which relate to uptake of wastewater reuse, for example, in Lebanon, research on a community on water reuse acceptance found that most of the population had more trust in their own judgement rather than any scientific evidence that was presented to them [37], and re-shaping this population judgement can be critical for overcoming the 'yuck' factor perceived by consuming products with large quantities of wastewater [38]. Gaining the acceptance and trust of the population may become more effective in driving wastewater reuse than through technical advancement alone [39], whilst an effective political and legal regime with well thought-out, designed and implemented political objectives and regulations can help to remove barriers to implementation and present opportunities to adopters of change [40, 41]. Therefore, in designing frameworks for circular water systems with increased wastewater use, there is a need to consider barriers and opportunities relating to political, economic, social, technological, environmental and legal contexts.

\section{Methodology}

To determine the business case for increased water reuse, it is important to understand and identify the thematic context of existing research on wastewater use and identify potential barriers that have already been highlighted by scholars in the field. This snapshot is developed through the adoption of a systematic literature review [42, 43]. A systematic review aims to produce reliable, replicable and transparent process and synthesis of information. The procedure followed in this paper is to take the case of wastewater use in agriculture and perform a systematic literature review on this topic. Following the collection of papers, a content analysis was performed using the PESTEL framework, with findings then synthesised and empirical searches for barriers applied. The justification for the cases and research and analysis procedures are documented in the remainder of this section. 


\section{The Context: Wastewater in Agriculture}

According to the United Nations analytical brief on wastewater management, there is no universally agreed definition on the term of wastewater [44]. However, widely used definitions from research and publications from Van de Hoek [45] and the United Nations Educational, Scientific and Cultural Organization (UNESCO) [7] conceptualise wastewater as a combination of domestic effluent (consisting of wastewater from kitchen and bathroom waste), water from commercial and industrial establishments (including effluent, stormwater and urban-run off) and agricultural effluent. The different wastewater releases occur in different quantities and with different qualities globally [7]. In this paper, we consider agricultural applications of wastewater and as such, domestic and commercial sources were excluded. However, the findings and processes developed in this paper can be applied to industrial and domestic wastewater settings as part of a future research plan.

\section{Systematic Review of Existing Research}

A systematic literature review was performed using the databases of Scopus and Web of Science, representing the two most popularly cited databases in academic research [46]. The literature search began with exploratory searches of search strings beginning with (1) water AND (re-use OR recycle OR repurpose); (2) water AND re-use; (3) wastewater AND re-use; (4) 'wastewater treatment' AND re-use; (5) water AND recycle; (6) 'wastewater treatment' AND recycle; (7) water AND repurpose. These searches provided hundreds of hits across multiple disciplines and refining the search terms led to the string of agriculture AND wastewater AND sustainab* AND (re-use OR reuse OR re use) being used for the database searches. The inclusion of sustainability was to ensure a wider focus of articles was represented and to filter papers which exclusively discussed technological advancement. After filtering for peer-reviewed journals and English language publications within the database filtering functions, 349 hits in Scopus and a further 111 hits in Web of Science were extracted from analysis. Following this process, a practical screening was applied:

- Duplicate articles were removed.

- Articles were published after 2014 to capture relevance for the emerging field of circular economy in resource usage to align with policy moves in the European Union.

- Abstracts and conclusions were screened for topics relating to practical implementation of wastewater reuse practices or wastewater technologies.

\section{Content Analysis and the Classification of Publications}

Content analysis was then used to classify discussions within passages of text against predetermined and pre-selected codes (inductive codes), which were supplemented by themes arising during the coding process (deductive codes) [47, 48]. Inductive codes were thematic and referred to the themes of debates within articles based on commonalities and differences between publications based on the PESTEL analysis. On this development, documents were coded according to the following criteria: 
- Political — referring to the political situation with regard to government, political stability and relations with other governments. Factors which affect the implementations of new technologies may include trade barriers, taxation and campaigns. Examples of sub-themes include governance and political cost.

- Economic - referring to how organisations reflect on the wider macroeconomic environment that they operate within. Factors such as national income, investment incentives, level of foreign investment, energy and water costs are critical for the uptake of wastewater reuse technologies. Example sub-themes include value chain, resource efficiency, price competition, value added, waste efficiency and circular economy.

- Societal-referring to trends in society and the impacts that wastewater reuse would have on wider society. This can be the result of societal values on conserving water and reducing wastewater, or considerations of how new technologies may impact on existing communities. Example sub-themes include impacts on community, community acceptance and public health.

- Technological - referring to adaptation and rates of change in technological contexts. For the water reuse process, new technologies can refer to developments of new processes, new wastewater treatment plants and new techniques to treat wastewater and distribute it for consumption. Example sub-themes include technological evaluations, comparing technologies and monitoring processes.

- Environmental - reducing environmental impacts often refers to pollution episodes and can be extended to wider ecosystem impacts. Example sub-themes include soil salinity and pollution avoidance.

- Legal - the legal factor concerns factors such as implementation of new laws, international treaties and enforcement of regulation. Example sub-themes include directives and legislation.

This critical step allows for the exploration on the state of the art and current progress of academic research in water reuse implementation in a wider circular water management development strategy. The second phase of analysis was a deductive phase, incorporating empirical codes relating specifically to identified barriers from in-depth screening of each article. These barriers were then analysed and contrasted in the context of water reuse and circularity in water resources.

\section{Results and Discussion}

The 50 sources articles were identified for further analysis according to process documented in Fig. 1. The remainder of the section documents the geographical distribution of articles and the categorisation of the main findings according to the PESTEL analysis. Finally, we document a way forward for a future research agenda to promote increased wastewater reuse as part of a circular economy framework.

\section{Geographical Scope of Studies}

The geography of studies including barriers to implementation in water reuse shows a wide distribution across countries which do not necessarily correspond to countries that might traditionally be associated to drought risk. The focus of barriers differs from region to region, 


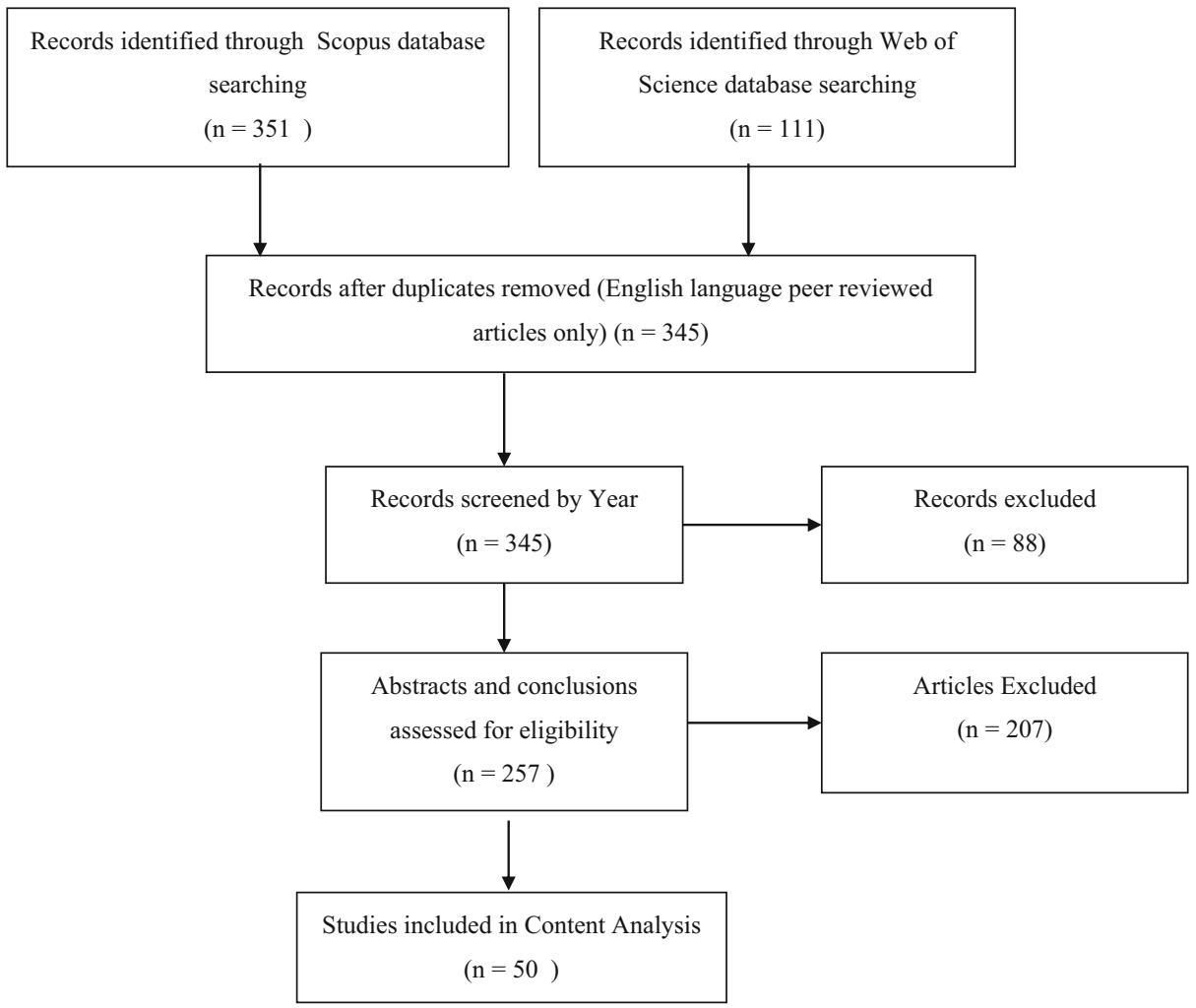

Fig. 1 Diagram of the literature review and article selection process

according to their prevalent interest and socio-economic characteristics of the region. It is noteworthy that general discussion on wastewater expands on countries of North America and Northern Europe, mainly due to the increased opportunities on research on the topic, from a financial and technical perspective. However, most of the barriers to implementation found a discourse in the context of arid or semi-arid areas and with a focus on Middle East, North Africa (MENA) and South Europe. The shift on climatic conditions towards arid areas is associated with pressures on water resources and therefore likely explains the focus on research exploring solution-oriented approaches that would enable the water reuse practices (Fig. 2).

\section{Categorisation of Barriers to Water Reuse Implementation (PESTEL Analysis)}

Articles were initially categorised according to their PESTEL theme. Fig. 3 highlights that the most common thematic focus cited in academic literature appears to be on technical feasibility of the practice. Social, political and economic aspects were also covered by the studies for at least a $10 \%$, whilst legal and environmental studies had lower representation compared to the other categories.

The results highlight that whilst there are studies which discuss the technical feasibility of implementing water reuse technologies, there is a relative lack of understandings on the sociopolitical infrastructure required to ensure that technical solutions could be applied in practice. 


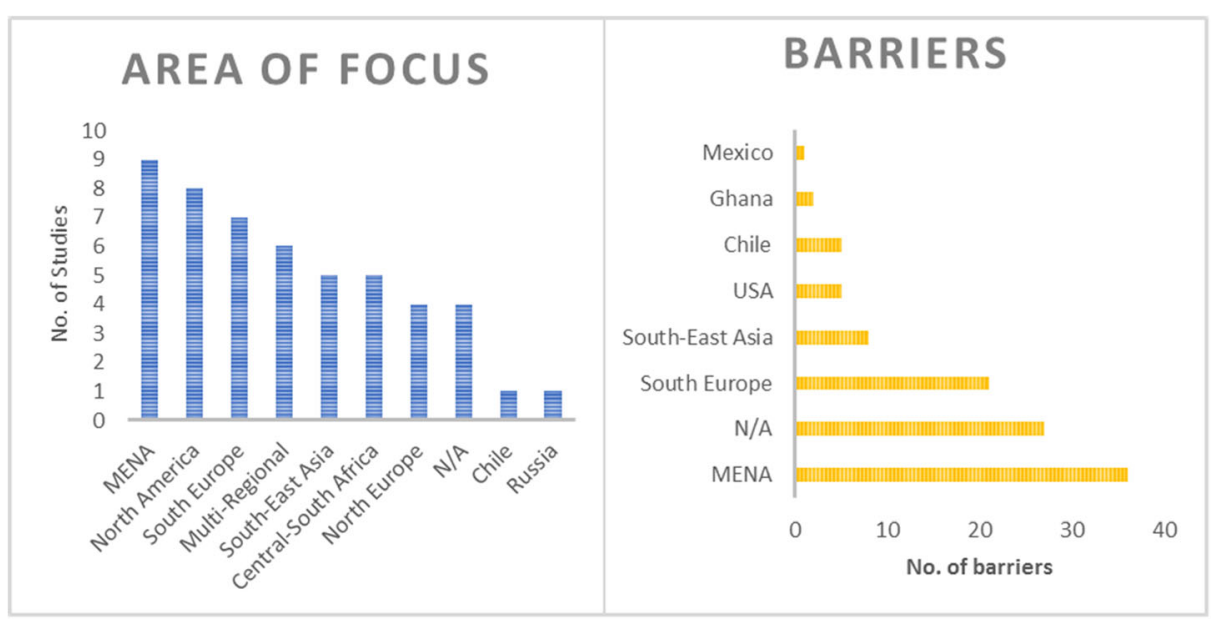

Fig. 2 Geographical distribution of the investigated studies (left) and the identified barriers (right) on wastewater reuse in agriculture (N/A, a geographic region was not specified; MENA, Middle East and North Africa)

This gap highlights evidence for potential barriers to the successful implementation of water reuse and the possibilities for extending these techniques towards a circular economy.

Fifty-six barriers to the uptake and implementation of water reuse in agriculture were categorised. Fig. 4 shows the distribution of barriers into categories based on the number of studies which identified them. Although the categorisation of the barriers was driven by the PESTEL analysis, additional technical barriers were identified in the lack of professional expertise for operation and maintenance of either the plants or reuse practices.

Social and economic barriers were most prominent with regard to consumers' acceptability, for example, through lack of knowledge regarding wastewater practices and costs associated with treatment facilities and services. However, overall, the aspects with the closest relationships were of economic and technological nature, discussing matters of economic feasibility of technological solutions, linking to the highlighted barriers of short-term financial barriers and longer-term economic sustainability barriers highlighted by Kirchherr et al. [28].

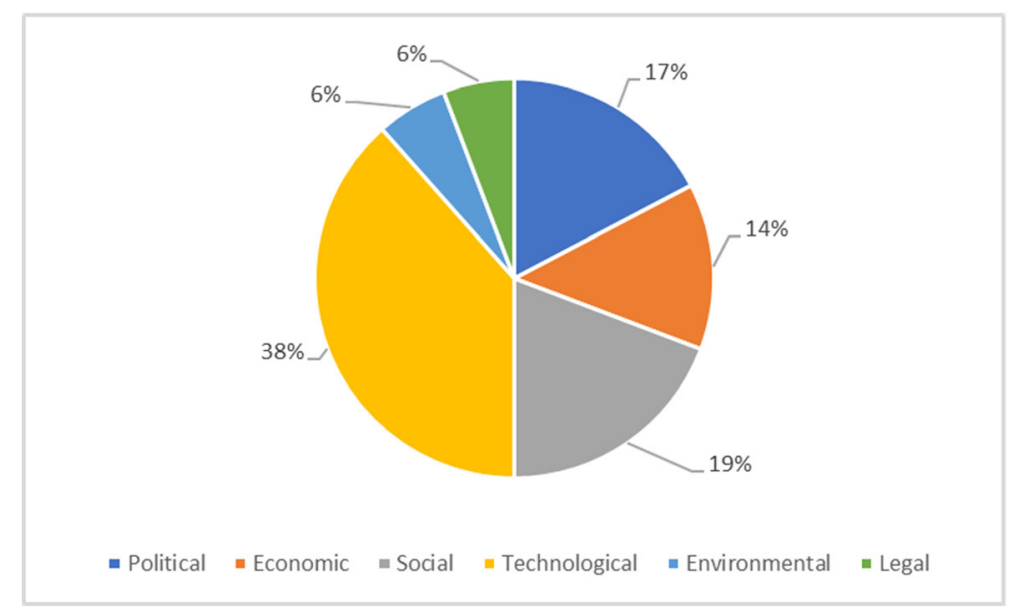

Fig. 3 Distribution of articles according to primary PESTEL theme 


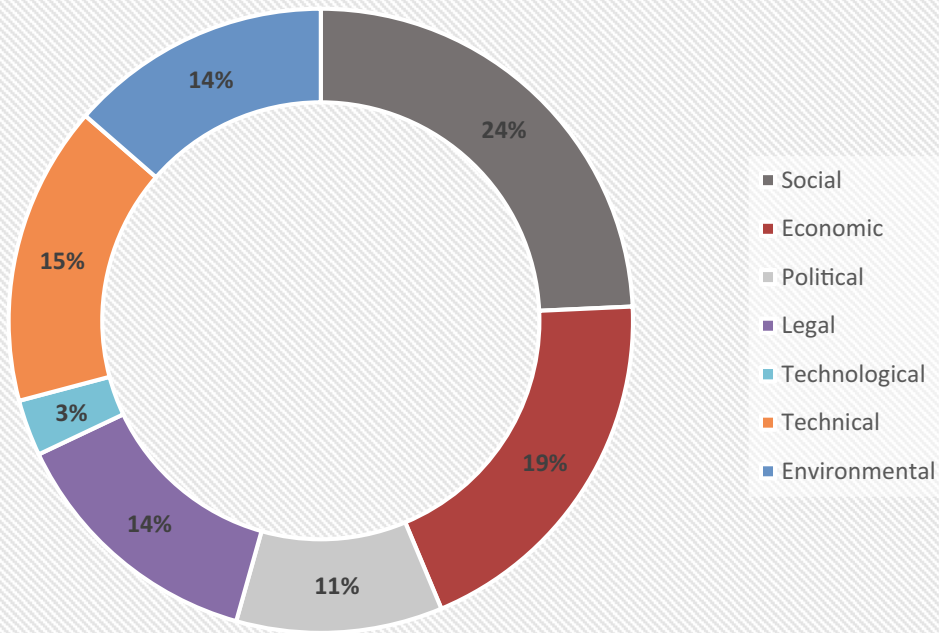

Fig. 4 Distribution of barriers in the literature according to their categorisation

As interrelations among the aspects were often observed in the papers explored in this systematic review, the remaining part of this section presents and discusses the results of the aspects according to the PESTEL analysis, with factors grouped together where there were strong interrelations and overlaps between these factors. Technical barriers have shown strong affinity with social challenges and therefore are discussed in the corresponding context.

\section{Governance and Legal Aspects}

Among legal and governance barriers 'the lack of implementation and absence of control of wastewater practices by the governmental authorities' and 'the lack of an adequate / absence of a regulatory framework' are reoccurring in the literature. Both aspects show the absence of a coherent approach to the management of water resources at different levels and scales. Despite the wide consensus in academia that the absence of a regulatory framework is a decisive factor for wastewater reuse in agriculture [49], governance structures entering into force for water reuse practices are experienced so far by few countries that started drafting guidelines on quality requirements for water reuse prevent to manage and reduce the risk related to its unsafe application in agriculture [50-52].

The existence of a regulatory framework can act as an enabling factor for wastewater uptake and implementation. Indeed, the incoherent formulation of laws and regulations could instead hinder progress towards a wider application of the practice. This is evidenced in the case of Colombia, in which the difficulty in downscaling of the regulation at the technical offices and the excessive bureaucratic work by the stakeholders intending performing water reuse stops its implementation [32].

However, the lack of political will or capacity to control and execute regulations can result in the use of untreated or poorly treated wastewater in practices that require restricted application $[53,54]$. In the case of Kuwait, absence of a complete regulatory framework and 
lack of control of water abstractions have resulted in overexploitation of groundwater with subsequent avoidance of wastewater reuse [55].

In the example of Italy, the regulations that have been introduced in 2003 regarding water reuse in agricultural, urban and industrial applications are not adequately differentiating the quality standards of wastewater, making it thus in many cases economically non-viable to make use of reclaimed water [56]. Lavrnić and Mancini [57] reported that the application of constructed wetlands $(\mathrm{CW})$ could have had a wider application in Italy, as the produced effluents, for the most cases, did not meet the standard quality requirements defined by the national regulations. This was attributed also to the lack of differentiation among the agricultural reuses of water, where effluents could have been used under restricted irrigation practices. In the case of South Korea, inadequate requirements in the regulations have deemed unsafe the direct use of treated wastewater in agriculture, making thus the practice almost absent [58].

Here, contrary to the experiences of Colombia by Jimenez et al. [32], the updates on the existing regulations in terms of minimum water requirements and stricter measures have been the enabling factor for wastewater uptake in the agricultural practices [38]. All in all, even in different aspects, addressing legislation gaps along with policy coherency among sectors is a key factor for increasing efficiency of policies $[19,59]$. Economic policies could promote differentiation of water tariffs according to its use to create incentives in wastewater uptake or a fit-for-purpose approach in legislation could forward encourage a wider range of wastewater applications by the adaption of water quality requirements to the purpose where human and environmental risk assessment could flexibly be adapted [56].

\section{Social Aspects}

Challenging for a wide application of wastewater in the circular economy settings is the public's distrust around the governmental authorities' competency and their commitment to properly implement reuse. Especially in countries where transparency is lacking, this aspect is negatively affecting the acceptance of water reuse on a large proportion of the population [37]. Central to better perform in community acceptance of innovative solution is the participatory process in which stakeholders are consulted and engaged and sustainable options are validated with the presence of affected and affecting stakeholders.

Lack of trust towards the public and control bodies builds a barrier between the policymakers and the implementers. If this is coupled with the lack of information on wastewater quality and procedures, a prejudiced perception against the value of the source [38] roots in the implementers. It has been generally observed that a lack of knowledge from farmers on the benefits and characteristics of wastewater and its treatment methods could lead to a lower acceptance of its uptake in their farms. On the contrary, effective communication on the positive impacts of its use could lead to higher levels of uptake. In Syria, the showcase of a successful application of treated wastewater on forage production has led to an increase in treated wastewater acceptability and use [54].

Promoting co-participatory approaches is crucial for the implementation of the project, as its absence is related to low acceptability by local actors $[49,60]$. Furthermore, data availability throughout a project and transparency of the operations of the wastewater treatment plants (WWTPs) could be a good starting point in gaining people's acceptance and trust. As a result, distrust of the farmers and susceptibility towards the level of treatment of the wastewater would ameliorate, leading to the broader acceptance of the practice $[39,61]$. Furthermore, the 
degree of stakeholders' acceptance influences the local authorities' capability for implementing such projects.

Effective cooperation among the stakeholders enables an open and transparent process of information flow and exchange of concerns, which is crucial for the success of socially and environmentally sensitive projects, such as wastewater application in agriculture [62]. A representative example of such social concern is the perceptions of risk on human health from wastewater reuse. Public's acceptance is heavily relying on the 'yuck' factor and the perceived health impacts associated with wastewater [38]. Proximity of use with human contact seems to be an important factor for its acceptance [37]. Similar concerns are also observed by farmers, who have shown to have a higher tendency of willingness for wastewater irrigation on crops cultivation that are not targeted directly for human consumption, such as alfalfa. Perceived impacts and benefits, however, are susceptible to the respective perceptions of a community, as people's acceptance is likely to be affected by other people's behaviours. In Italy, farmers perceived greater benefits from wastewater irrigation on a local application, as the degree of perception of risks is similar for the local community [63].

The lack of technical expertise available has also been found to influence decisively the potential of water reuse. This is especially evident in low-income countries, where the connection between universities and industries is weak, leading to a gap between education and its application for society [53]. An enabling factor, therefore, is the promotion of training and educational programmes or workshops in regard to wastewater technicalities to ensure that the personnel has acquired the required skills for a smooth and appropriate operability of wastewater projects and WWTPs.

\section{Economic-Technological Aspects}

Although majority of the articles referred to technological advancements and application of wastewater treatment, challenges to overcome it are few. Only 3 out of the 56 barriers were covering technological aspects. This is in line with previous research on barriers to circular economy practices by Kirchherr et al. [28]. Here, economic and technological factors are discussed in conjunction together-in terms of short-term financial investment costs and longer-term economic profitability of shifting practices.

Technological advances in the field of wastewater treatment have been largely reported, and technologies are still associated with high costs both in terms of technological assets and operation and maintenance of the plant in which the technology is installed. Fit-for-purpose solutions could be a solution to minimise these costs. Indeed, not all practices for reuse require the same water quality requirements. For example, secondary wastewater treatment with water treatment sludge (WTS) has the potential of reuse in various applications, such as cement production, manufacturing or agriculture. The appropriate end use if the sludge is defined, among others, by its quality characteristics, especially its chemical status, and the level of treatment [64].

Financially, sound solutions to a fitted wastewater treatment can also be found for areas with poor infrastructure or small communities that cannot bear the costs of advanced treatment technologies. Taking influent wastewater quality, climatic and socio-economic characteristics into consideration, a fit-for-purpose approach could provide an affordable renewable water resource. For example, a water stabilisation pond (WSP) cost depends on the price of the land, where at the same time it does not require technically skilled personnel and is not energy demanding, making it thus a viable solution for rural and remote areas where land is 
characterised by low prices [65]. Another example is that of constructed wetlands, which could be an affordable solution to a more advanced treatment in small communities when combined with another pre-treatment technology $[57,66]$. As they are dependent on temperature, among others, they have been found efficient in pollutant removal in warmer regions, such as the Mediterranean countries [67]. In areas where groundwater pumping has been overexploited, tertiary treatment could lead to an increase in water availability, leading thus to higher agricultural capacity [68].

However, the economic feasibility of a wastewater reuse project is often a decisive factor for its realisation [69]. Installation and maintenance costs of supply systems, such as the transportation costs, can be challenging, especially in areas with poor infrastructure [18]. Long distances between the WWTP, the farms and the disposal sites demand pipelines and energy for pumping, among others, which can be cost demanding [70]. Due to the lack of financial capacity in maintaining large central WWT facilities, low-income countries tend to switch to decentralised small-scale transportation and treatment facilities [53].

It is often the case that the price of wastewater is higher than freshwater. This has a particularly deterrent effect on farmers, who are generally not willing to pay the higher price $[39,69]$. In addition, the low preference of wastewater irrigated products by consumers leads to their relative marketable disadvantage [54]. In regions where conventional water supply is cheap or in some cases even free of charge, the higher price of reclaimed water, coupled with the distrust of its quality, makes it an even less appealing source of water [38]. On the other hand, new research has shown that in arid areas, where the value of water, as well as electricity, is high, advanced technologies, such as the microbial fuel cell (MFC), could be profitable for farmers [71]. Tertiary treatment could be a viable solution to areas where freshwater availability is declining. In coastal areas, like Tunisia or the Gaza Strip, groundwater has been excessively pumped, resulting in increased salinity of the water. Incorporating the use of advanced treated wastewater in the water resources management strategy could increase water availability [68].

\section{Environmental Aspects}

Environmental factors, such as the seasonal variation of the effluent and composition, could prove a limitation to its use if not proper technologies are adopted. The upscaling of the application area would enable larger wastewater volumes and thus become a limiting factor for smaller communities. Upscaling of the reuse concept also leads to higher transportation and infrastructure costs [60] to guarantee the practice of wastewater. However, densely populated urban environments are a more reliable source of effluent but may face limitations in land availability that treatment plants facilities require to operate successfully and at sufficient capacity.

Nutrient imbalance in the effluent is another factor that brings concerns to water reuse in agriculture. High levels of salinity, heavy metals and newer contaminants of emerging concern like pharmaceuticals and antimicrobial resistant bacteria could result in either accumulation in soil and crops or contaminating microbiologically the environment thus (re)introducing the contaminants through the food chain. However, recent studies have shown that an appropriate water reuse management associated with suitable treatment technology could reduce sensibly this risk [72]. Highly treated wastewater can result in macro and micro nutrients loss essential components for water reuse activities in low- to middle-income countries where such elements would guarantee plant growth and yield with no use of costly mineral fertilisers [73]. 


\section{The Way Forward}

Through this literature review, the authors identified and categorised main barriers challenging water reuse implementation in agriculture. The aim was to enable a coherent prioritisation in the focus and actions required if wastewater must be pushed in the circular economy of water. Nevertheless, the wide range of challenges are subject to the geo-political and socio-economic characteristics of each region or country. The understanding of the status in quo and the actual configuration of the societal standing remain essential for assigning the optimal weight on different policies actions and adopted solutions.

The vast range of different barriers identified in the literature are presented in a segmental form of the overall landscape for the application of wastewater reuse practices in agriculture. Previous barrier research is often compartmentalised according to barriers of specific themes and the implications for future action, therefore omitting other barriers that are deemed to be unconnected or not sufficiently connected to the research study. Following the work of Miller [74], an overview of the different thematic interrelations was combined into a set of configurations. These configurations were then mapped to show their potential interconnections and identify potential actions which can overcome the barriers to wastewater reuse identified in this review. The different configurations are mapped in Fig. 5, following the approach of a schematic pathway proposed by Gond et al. [75]. The configurations are presented as an aggregate of the main identified barrier categories and interactions to enable a clearer applicability of the proposed configuration map, as opposed to a complex mapping of all the possible sub-formats displaying all the possible interactions of the barrier categories [76].

Since literature suggests technological solutions already be available, the initial configuration assumes this barrier to be already addressed, and in general, we consider the financial viability as distinct barriers which require intervention at a political level regarding incentives and subsides. Short-term financial barriers can be offset by the provision of subsidies and investment schemes which tackle the up-front costs of re-designing production processes, irrigation systems and water infrastructure systems that enable greater uptake of wastewater reuse. Longer-term economic sustainability of wastewater reuse requires a longer-term framework that considers future cost increases of water resources, the availability and access of

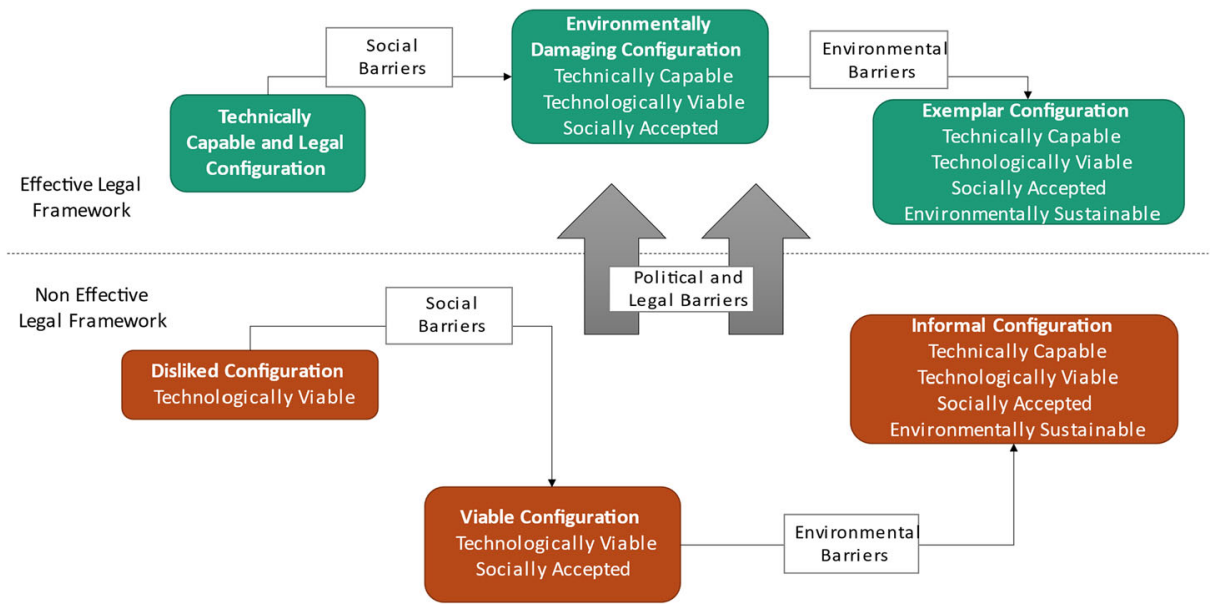

Fig. 5 A course of overcoming barriers, starting from primary and leading to advanced configuration 
freshwater and potential future regulatory interventions such as taxes on freshwater abstraction or wastewater discharge.

In the case where an effective regulatory framework and the know-how for implementing already existing technologies that will allow the safe reuse of wastewater are in place (technically capable and legal configuration), priority should be given to increasing the acceptance of the practice by the end users and possible consumers of the products. As environmental barriers were less addressed in the literature compared to the social barriers (14 and 24\%, respectively), it was assumed that efforts towards environmental barriers breakdown are relevant and ongoing. Moving forward, social barriers should initially be addressed and thus become a priority in designing wastewater reuse schemes.

One decisive factor for the successful uptake of wastewater in water reuse practices is the presence of a binding and effective legal framework [77, 78]. Affordable technologies that ensure clean wastewater and a societal capacity and maturity for using these technologies are not adequate to ensure their effective use. Well-established regulations that pertain quality requirements for the protection of human and environmental health should be put in force. In the case of the underground configuration, most of the barriers have been addressed, but the practice is not well regulated, yet it is shown that regulatory pressures can be a powerful (if not the most powerful) driver for shifting towards sustainable practices for companies, in particular SMEs. Focus should, therefore, be given to create a legal system which will include legal penalisation or financial incentives to wastewater reuse. Simultaneously, the presence of wastewater application in the political agenda is required to establish a beneficial top-down approach, along with the promotion of political transparency.

\section{Conclusions and Recommendations for Future Work}

A circular economy approach to water reuse be positioned as a concept to help solve the water resource crisis by linking circular economy as a political aim with one which can be delivered through action $[3,5,6]$. As part of a fit-for-purpose approach, financing high-cost technologies could be targeted to the water reuse purposes that primarily demand them, whereas technologies that are more financially friendly can be used on a wider scale. Our findings from the agriculture sector suggest that the technical feasibility of wastewater reuse techniques is inextricably linked to the short-term financial viability as well as the long-term economic sustainability of transitions towards circular economic practices.

Given that a circular economy approach to wastewater reuse can be crucial in response to the critical challenges in managing limited water resources, there is a need to ensure appropriate legal and political support for such schemes and design policies and laws which help to overcome short-term financial barriers. From an ecological modernisation perspective, it is important to ensure that transitions to circular economy practices of wastewater reuse in the agricultural sector benefit the wider environment in terms of pollution reduction. An economically and environmentally sustainable scheme for incentivising the deployment of feasible technologies will help to address the water challenges in the agricultural sector, as well as potentially providing blueprints for deployment in other settings. Finally, a social need to gain acceptance for wastewater usage is key and gaining the necessary changes towards coherent governance processes is necessary to effectively manage wastewater for reuse purposes. Crucial is also the application of human and environmental impact assessment and efficient 
resource consumption, balanced against community acceptance and positive attitudes towards use of wastewater.

Future work should be focused on extending research towards developing a framework for organisational decision-making processes that could be applied to companies and utilities and address the gap between theoretical and actual applications of technologies. This requires the identification of primary stakeholders in society across the political, economic, social, technological, environmental and legal sectors to input into future research designs for increased wastewater reuse as part of a wider sustainability strategy. Covering these goals and including a range of stakeholders are crucial to ensure there are applications of these technologies beyond the agricultural sector. A comprehensive stakeholder engagement framework that covers key actors from policy, business, societal and community organisations as well as environmental protection authorities and associations will be crucial for developing legal frameworks and ensure the economically feasible, technologically viable and long-term sustainable wastewater reuse practices and deliver a circular economy of water consumption across a range of industries.

Author Contribution The authors confirm contribution to the paper as follows: study conception and design: Morris; data collection: Morris and Georgiou; analysis and interpretation of results: Morris, Caucci and Guenther; draft manuscript preparation: Georgiou and Caucci; critical revision of the manuscript: Morris, Caucci and Guenther. All authors reviewed the results and approved the final version of the manuscript.

Funding Open Access funding enabled and organized by Projekt DEAL. The authors gratefully acknowledge the support of the Project Organisational Decision-Making in Water Reuse for Smart Cities (SMARTWaterDomain), funded by the German Federal Ministry of Education and Research (BMBF) and supported by the EIG-Concert Japan. Grant reference: 01DR20007B.

Availability of Data and Material (Data Transparency) The data that support the findings of this study are available from the corresponding author, upon reasonable request.

Code Availability (Software Application or Custom Code) There is no associated code with the production of this article.

\section{Declarations}

Ethics Approval Not applicable for this paper.

Consent to Participate Not applicable for this paper.

Consent to Publish On behalf of all the authors, the corresponding author confirms that neither the article nor portions of it have been previously published elsewhere; the manuscript is not under consideration for publication in another journal, and all authors consent to the publication of the manuscript in Circular Economy and Sustainability should the article be accepted by the Editor-in-chief upon completion of the refereeing process.

Conflict of Interest The authors declare no competing interests.

Open Access This article is licensed under a Creative Commons Attribution 4.0 International License, which permits use, sharing, adaptation, distribution and reproduction in any medium or format, as long as you give appropriate credit to the original author(s) and the source, provide a link to the Creative Commons licence, and indicate if changes were made. The images or other third party material in this article are included in the article's Creative Commons licence, unless indicated otherwise in a credit line to the material. If material is not included 
in the article's Creative Commons licence and your intended use is not permitted by statutory regulation or exceeds the permitted use, you will need to obtain permission directly from the copyright holder. To view a copy of this licence, visit http://creativecommons.org/licenses/by/4.0/.

\section{References}

1. Rosa L, D'Odorico P (2019) The water-energy-food nexus of unconventional oil and gas extraction in the Vaca Muerta Play, Argentina. J Clean Prod 207:743-750. https://doi.org/10.1016/j.jclepro.2018.10.039

2. Govindan K, Hasanagic M (2018) A systematic review on drivers, barriers, and practices towards circular economy: a supply chain perspective. Int J Prod Res 56:278-311. https://doi.org/10.1080/00207543.2017. 1402141

3. Cainelli G, D’Amato A, Mazzanti M (2020) Resource efficient eco-innovations for a circular economy: evidence from EU firms. Res Policy 49:103827. https://doi.org/10.1016/j.respol.2019.103827

4. European Commission (2020) New circular economy strategy. https://ec.europa.eu/environment/circulareconomy/. Accessed 17 Jun 2020

5. Batista L, Bourlakis M, Liu Y, Smart P, Sohal A (2018) Supply chain operations for a circular economy. Prod Plan Control 29:419-424. https://doi.org/10.1080/09537287.2018.1449267

6. Genovese A, Acquaye AA, Figueroa A, Koh SCL (2017) Sustainable supply chain management and the transition towards a circular economy: evidence and some applications. Omega 66:344-357. https://doi.org/ 10.1016/j.omega.2015.05.015

7. UNESCO (2017) Wastewater: the untapped resource. United Nations, Paris

8. UNESCO World Water Assessment Programme, Water Europe (2019) Water in the 2030 agenda: how can Europe act? Brussels, Paris

9. Commission of the European Union (2011) A resource-efficient Europe-flagship initiative under the Europe 2020 strategy

10. Lavrnić S, Zapater-Pereyra M, Mancini ML (2017) Water scarcity and wastewater reuse standards in Southern Europe: focus on agriculture. Water Air Soil Pollut 228:251. https://doi.org/10.1007/s11270-0173425-2

11. Hoekstra AY (2017) Water footprint assessment in supply chains. In: Bouchery Y, Corbett C, Fransoo J, Tarkan (eds) Sustainable supply chains. Springer, Cham, pp 65-85

12. Hagenvoort J, Ortega-Reig M, Botella S, García C, de Luis A, Palau-Salvador G (2019) Reusing treated waste-water from a circular economy perspective - the case of the real Acequia de Moncada in Valencia (Spain). Water 11:1830. https://doi.org/10.3390/w11091830

13. Schaltegger S, Viere T, Zvezdov D (2012) Tapping environmental accounting potentials of beer brewing: information needs for successful cleaner production. J Clean Prod 29-30:1-10. https://doi.org/10.1016/j. jclepro.2012.02.011

14. Núñez J, Yeber M, Cisternas N, Thibaut R, Medina P, Carrasco C (2019) Application of electrocoagulation for the efficient pollutants removal to reuse the treated wastewater in the dyeing process of the textile industry. J Hazard Mater 371:705-711. https://doi.org/10.1016/j.jhazmat.2019.03.030

15. Bravo G (2014) The human sustainable development index: new calculations and a first critical analysis. Ecol Indic 37:145-150

16. Morris J (2019) Developing and exploring indicators of water sustainable development. Heliyon 5:e01778. https://doi.org/10.1016/j.heliyon.2019.e01778

17. Intriago JC, López-Gálvez F, Allende A, Vivaldi GA, Camposeo S, Nicolás Nicolás E, Alarcón JJ, Pedrero Salcedo F (2018) Agricultural reuse of municipal wastewater through an integral water reclamation management. J Environ Manag 213:135-141. https://doi.org/10.1016/j.jenvman.2018.02.011

18. Zhang Y, Shen Y (2019) Wastewater irrigation: past, present, and future. Wiley Interdiscip Rev Water 6: e1234. https://doi.org/10.1002/wat2.1234

19. Kirschke S, Zhang L, Meyer K (2018) Decoding the wickedness of resource nexus problems - examples from water-soil nexus problems in China. Resources 7:67. https://doi.org/10.3390/resources7040067

20. Korhonen J (2008) Reconsidering the economics logic of ecological modernization. Environ Plan A 40: 1331-1346

21. Hobson K, Lynch N (2016) Diversifying and de-growing the circular economy: radical social transformation in a resource-scarce world. Futures 82:15-25. https://doi.org/10.1016/j.futures.2016.05.012

22. WHO (2006) WHO guidelines for the safe use of wastewater, excreta and greywater. Wastewater Agric 2

23. Hanjra MA, Blackwell J, Carr G, Zhang F, Jackson TM (2012) Wastewater irrigation and environmental health: implications for water governance and public policy. Int J Hyg Environ Health 215:255-269. https:// doi.org/10.1016/j.ijheh.2011.10.003 
24. Foster JB (2012) The planetary rift and the new human exemptionalism: a political-economic critique of ecological modernization theory. Organ Environ 25:211-237. https://doi.org/10.1177/1086026612459964

25. Hettiarachchi H, Caucci S, Ardakanian R (2018) Safe use of wastewater in agriculture: the golden example of nexus approach. In: Hettiarachchi H, Ardakanian R (eds) Safe use of wastewater in agriculture: from concept to implementation. Springer International Publishing, Cham, pp 1-11

26. WWAP (2017) The United Nations world water development report 2017: wastewater, the untapped resource. United Nations World Water Assessment Programme, Paris

27. York R, Mancus P (2009) Critical human ecology: historical materialism and natural laws. Sociol Theory

28. Kirchherr J, Piscicelli L, Bour R, Kostense-Smit E, Muller J, Huibrechtse-Truijens A, Hekkert M (2018) Barriers to the circular economy: evidence from the European Union (EU). Ecol Econ 150:264-272. https:// doi.org/10.1016/j.ecolecon.2018.04.028

29. Ormazabal M, Prieto-Sandoval V, Puga-Leal R, Jaca C (2018) Circular economy in Spanish SMEs: challenges and opportunities. J Clean Prod 185:157-167. https://doi.org/10.1016/j.jclepro.2018.03.031

30. Ranta V, Aarikka-Stenroos L, Ritala P, Mäkinen SJ (2018) Exploring institutional drivers and barriers of the circular economy: a cross-regional comparison of China, the US, and Europe. Resour Conserv Recycl 135: 70-82. https://doi.org/10.1016/j.resconrec.2017.08.017

31. Ruiz-Rosa I, García-Rodríguez FJ, Antonova N (2020) Developing a methodology to recover the cost of wastewater reuse: a proposal based on the polluter pays principle. Util Policy 65:101067. https://doi.org/10. 1016/j.jup.2020.101067

32. Jiminez N, Caucci S, Hettiarachchi H (2018) Safe use of wastewater in agriculture: exchanging knowledge in Colombia. In: Proceedings, Bogotá, Colombia, 27-28 November 2018. Dresden: United Nations University Institute for Integrated Management of Material Fluxes and of Resources (UNU-FLORES)

33. Hueske A-K, Guenther E (2015) What hampers innovation? External stakeholders, the organization, groups and individuals: a systematic review of empirical barrier research. Manag Rev Q 65:113-148. https://doi. org/10.1007/s11301-014-0109-5

34. Hueske A-K, Guenther E (2018) Balancing comprehensiveness and parsimony: towards a context-specific barrier identification across multiple levels combined with complexity reduction through barrier groups. J Eng Technol Manag 49:46-59. https://doi.org/10.1016/j.jengtecman.2018.05.002

35. Hueske A-K, Endrikat J, Guenther E (2015) External environment, the innovating organization, and its individuals: a multilevel model for identifying innovation barriers accounting for social uncertainties. J Eng Technol Manag 35:45-70. https://doi.org/10.1016/j.jengtecman.2014.10.001

36. Herrmann J, Guenther E (2017) Exploring a scale of organizational barriers for enterprises' climate change adaptation strategies. J Clean Prod 160:38-49. https://doi.org/10.1016/j.jclepro.2017.03.009

37. Massoud MA, Kazarian A, Alameddine I, Al-Hindi M (2018) Factors influencing the reuse of reclaimed water as a management option to augment water supplies. Environ Monit Assess 190(9):531. https://doi.org/ 10.1007/s10661-018-6905-y

38. Saliba R, Callieris R, D'Agostino D, Roma R, Scardigno A (2018) Stakeholders' attitude towards the reuse of treated wastewater for irrigation in Mediterranean agriculture. Agric Water Manag 204:60-68. https://doi. org/10.1016/j.agwat.2018.03.036

39. Massoud MA, Terkawi M, Nakkash R (2019) Water reuse as an incentive to promote sustainable agriculture in Lebanon: stakeholders' perspectives. Integr Environ Assess Manag 15:412-421. https://doi.org/10.1002/ ieam.4131

40. Lazarevic D, Valve H (2017) Narrating expectations for the circular economy: towards a common and contested European transition. Energy Res Soc Sci 31:60-69. https://doi.org/10.1016/j.erss.2017.05.006

41. Domenech T, Bahn-Walkowiak B (2019) Transition towards a resource efficient circular economy in Europe: policy lessons from the EU and the member states. Ecol Econ 155:7-19. https://doi.org/10.1016/ j.ecolecon.2017.11.001

42. Tranfield D, Denyer D, Smart P (2003) Towards a methodology for developing evidence-informed management knowledge by means of systematic review. Br J Manag 14:207-222. https://doi.org/10. $1111 / 1467-8551.00375$

43. Fink A (2010) Conducting research literature reviews: from the internet to paper. SAGE Publications

44. UN (2015) Wastewater management: a UN-water analytical brief. In: UN-Water. https:/www.unwater.org/ publications/wastewater-management-un-water-analytical-brief/. Accessed 8 Oct 2020

45. Van der Hoek W (2004) A framework for a global assessment of the extent of wastewater irrigation: the need for a common wastewater typology

46. Martín-Martín A, Orduna-Malea E, Thelwall M, Delgado López-Cózar E (2018) Google Scholar, Web of Science, and Scopus: a systematic comparison of citations in 252 subject categories. J Inf Secur 12:11601177. https://doi.org/10.1016/j.joi.2018.09.002

47. Krippendorff K (1980) Validity in content analysis 
48. Sharma S (2000) Managerial interpretations and organizational context as predictors of corporate choice of environmental strategy. Acad Manag J 43:681-697. https://doi.org/10.2307/1556361

49. Winkler MS, Jackson D, Sutherland D, Lim JMU, Srikantaiah V, Fuhrimann S, Medlicott K (2017) Sanitation safety planning as a tool for achieving safely managed sanitation systems and safe use of wastewater. WHO South-East Asia J Public Health 6:34 40. https://doi.org/10.4103/2224-3151.213790

50. Inbar Y (2007) New standards for treated wastewater reuse in Israel. In: Zaidi MK (ed) Wastewater reuserisk assessment, decision-making and environmental security. Springer Netherlands, Dordrecht, pp 291-296

51. USEPA (2012) Guidelines for water reuse. US Environmental Protection Agency, Anchorage

52. Commission of the European Union (2014) Communication from the Commision on the European citizens' initiative "Water and sanitation are a human right! Water is a public good, not a commodity!"

53. Khalid S, Shahid M, Natasha BI, Sarwar T, Shah AH, Niazi NK (2018) A review of environmental contamination and health risk assessment of wastewater use for crop irrigation with a focus on low and highincome countries. Int J Environ Res Public Health 15:1-36. https://doi.org/10.3390/ijerph15050895

54. Hussain MI, Muscolo A, Farooq M, Ahmad W (2019) Sustainable use and management of nonconventional water resources for rehabilitation of marginal lands in arid and semiarid environments. Agric Water Manag 221:462-476

55. Aliewi A, El-Sayed E, Akbar A, Hadi K, Al-Rashed M (2017) Evaluation of desalination and other strategic management options using multi-criteria decision analysis in Kuwait. Desalination 413:40-51. https://doi. org/10.1016/j.desal.2017.03.006

56. Ait-Mouheb N, Bahri A, Ben TB, Benyahia B, Bourrié G, Cherki B, Condom N, Declercq R, Gunes A, Héran M, Kitir N, Molle B, Patureau D, Pollice A, Rapaport A, Renault P, Riahi K, Romagny B, Sari T, Sinfort C, Steyer JP, Talozi S, Topcuoglu B, Turan M, Wéry N, Yıldırım E, Harmand J (2018) The reuse of reclaimed water for irrigation around the Mediterranean Rim: a step towards a more virtuous cycle? Reg Environ Chang 18:693-705. https://doi.org/10.1007/s10113-018-1292-z

57. Lavrnić S, Mancini ML (2016) Can constructed wetlands treat wastewater for reuse in agriculture? Review of guidelines and examples in South Europe. Water Sci Technol 73:2616-2626. https://doi.org/10.2166/wst. 2016.089

58. Jeong H, Kim H, Jang T (2016) Irrigation water quality standards for indirect wastewater reuse in agriculture: a contribution toward sustainable wastewater reuse in South Korea. Water Switz 8(4):169. https://doi.org/10.3390/w8040169

59. Amponsah O, Vigre H, Schou TW, Boateng ES, Braimah I, Abaidoo RC (2015) Assessing low quality water use policy framework: case study from Ghana. Resour Conserv Recycl 97:1-15. https://oi.org/10. 1016/j.resconrec.2015.01.009

60. Barbosa B, Costa J, Fernando AL, Papazoglou EG (2015) Wastewater reuse for fiber crops cultivation as a strategy to mitigate desertification. Ind Crop Prod 68:17-23. https://doi.org/10.1016/j.indcrop.2014.07.007

61. Benavides L, Avellán T, Caucci S, Hahn A, Kirschke S, Müller A (2019) Assessing sustainability of wastewater management systems in a multi-scalar, transdisciplinary manner in Latin America. Water 11: 249. https://doi.org/10.3390/w11020249

62. Caucci S, Zhang L, Locher-Krause L, Hülsmann S (2020) Sustainable development as the ultimate target of adopting a nexus approach to resources management. In: Lehmann H (ed) Sustainable development and resource productivity. Routledge, pp 67-79

63. Michetti M, Raggi M, Guerra E, Viaggi D (2019) Interpreting farmers' perceptions of risks and benefits concerning waste water reuse for irrigation: a case study in Emilia-Romagna (Italy). Water Switz 11(1):108. https://doi.org/10.3390/w11010108

64. Ahmad T, Ahmad K, Alam M (2016) Sustainable management of water treatment sludge through 3'R' concept. J Clean Prod 124:1-13. https://doi.org/10.1016/j.jclepro.2016.02.073

65. Das S, Bokshi S (2017) Sustainable waste water treatment in developing countries: a case study of IIT Kharagpur Campus. J Inst Eng India Ser A 98:127-134. https://doi.org/10.1007/s40030-017-0197-z

66. Sindilariu PD, Brinker A, Reiter R (2009) Factors influencing the efficiency of constructed wetlands used for the treatment of intensive trout farm effluent. Ecol Eng 35:711-722. https://doi.org/10.1016/j.ecoleng. 2008.11.007

67. Ávila C, Garfi M, García J (2013) Three-stage hybrid constructed wetland system for wastewater treatment and reuse in warm climate regions. Ecol Eng 61:43-49. https://doi.org/10.1016/j.ecoleng.2013.09.048

68. Al-Juaidi AE, Kaluarachchi JJ, Mousa AI (2014) Hydrologic-economic model for sustainable water resources management in a coastal aquifer. J Hydrol Eng 19:1-12. https://doi.org/10.1061/(ASCE)HE. 1943-5584.0000960

69. El Moussaoui T, Wahbi S, Mandi L, Masi S, Ouazzani N (2019) Reuse study of sustainable wastewater in agroforestry domain of Marrakesh city. J Saudi Soc Agric Sci 18:288-293. https://doi.org/10.1016/j.jssas. 2017.08.004 
70. Lee EJ, Criddle CS, Geza M, Cath TY, Freyberg DL (2018) Decision support toolkit for integrated analysis and design of reclaimed water infrastructure. Water Res 134:234-252. https://doi.org/10.1016/j.watres. 2018.01.037

71. Abourached C, English MJ, Liu H (2016) Wastewater treatment by microbial fuel cell (MFC) prior irrigation water reuse. J Clean Prod 137:144-149. https://doi.org/10.1016/j.jclepro.2016.07.048

72. Rizzo L, Malato S, Antakyali D, Beretsou VG, Đolić MB, Gernjak W, Heath E, Ivancev-Tumbas I, Karaolia P, Lado Ribeiro AR, Mascolo G, McArdell CS, Schaar H, Silva AMT, Fatta-Kassinos D (2019) Consolidated vs new advanced treatment methods for the removal of contaminants of emerging concern from urban wastewater. Sci Total Environ 655:986-1008. https://doi.org/10.1016/j.scitotenv.2018.11.265

73. Vergine P, Salerno C, Libutti A, Beneduce L, Gatta G, Berardi G, Pollice A (2017) Closing the water cycle in the agro-industrial sector by reusing treated wastewater for irrigation. J Clean Prod 164:587-596. https:// doi.org/10.1016/j.jclepro.2017.06.239

74. Miller D (1986) Configurations of strategy and structure : towards a synthesis. Strateg Manag J 7:233-249

75. Gond J-P, Grubnic S, Herzig C, Moon J (2012) Configuring management control systems: theorizing the integration of strategy and sustainability. Manag Account Res 23:205-223. https://doi.org/10.1016/j.mar. 2012.06.003

76. Miller D (1996) Configurations revisited. Strateg Manag J 17:505-512. https://doi.org/10.1002/(SICI)10970266(199607)17:7<505::AID-SMJ852>3.0.CO;2-I

77. Halalsheh M, Kassab G (2018) Policy and the governance framework for wastewater irrigation: Jordanian experience. In: Hettiarachchi H, Ardakanian R (eds) Safe Use of wastewater in agriculture. Springer, Cham, pp 75-99

78. van Karnenbeek L, Salet W, Majoor S (2020) Wastewater management by citizens: mismatch between legal rules and self-organisation in Oosterwold. J Environ Plan Manag. https://doi.org/10.1080/09640568.2020. 1829572 